\title{
Leadership style and leadership effectiveness: Does cultural intelligence moderate the relationship?
}

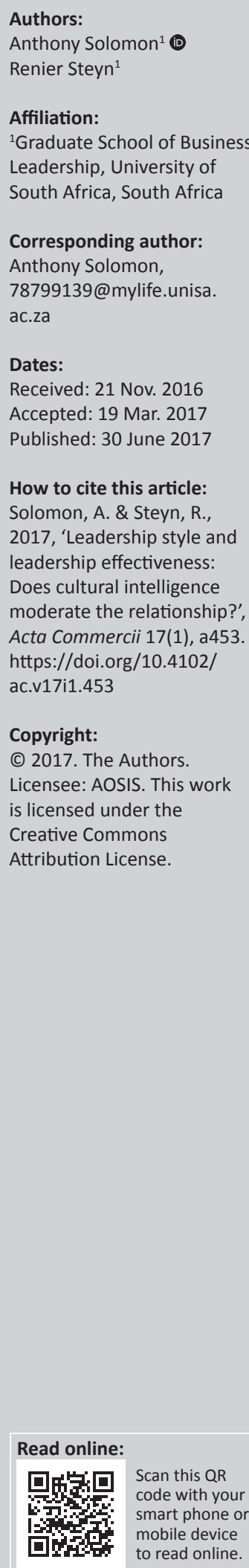

Orientation: In an age where subordinate cultural heterogeneity has become the norm, cultural intelligence might assist leaders to improve their effectiveness.

Research purpose: This research investigated whether leader cultural intelligence moderated the relationship between leadership style (as represented by empowerment and direction) and leadership effectiveness.

Motivation for the study: Although the literature on cultural intelligence has been increasing in quantity, there remained a gap in the understanding of the relationship between leader cultural intelligence, the empowering and directive leadership styles and leadership effectiveness.

Research design, approach and method: A quantitative methodology with a cross-sectional survey design was followed. Data were obtained from 1140 staff members employed at 19 South African organisations. Factorial, correlational and moderated multiple regression analyses were performed.

Main findings: Although leader cultural intelligence and its dimensions do not moderate the relationship between empowering leadership and leadership effectiveness, they do nonetheless negatively moderate the relationship between directive leadership and leadership effectiveness. This moderation was, however, assessed to be of no practical significance.

Practical and managerial implications: As leader cultural intelligence did not act as an important influencer of the relationship between leadership style and leadership effectiveness, it appeared that effective leaders may have used their cultural intelligence to actually guide the selection of an effective leadership style in the first place.

Contribution and value add: Being one of the first studies to explore the moderating effect of leader cultural intelligence on the relationship between leadership style and leadership effectiveness, this research has made a valuable contribution to building both the cultural intelligence and leadership knowledge bases.

\section{Introduction}

Leaders are central to organisational achievement (Araujo-Cabrera, Suarez-Acosta \& AguiarQuintana 2016; Muchiri et al. 2011; Murschetz 2005); consequently, it is vital that they be effective. However, a lack of certainty prevails as to what is necessary for one to be an effective leader (Rosete \& Ciarrochi 2005). This situation is exacerbated in that there is 'neither a universally accepted approach to nor definition of' leadership effectiveness (Mesterova et al. 2015:109). Accordingly, leadership effectiveness is manifested as a relative judgement predicated upon both description and evaluated characteristics (Oyinlade 2006).

A particular challenge in the domain of leadership effectiveness has been the assessment thereof. Specifically, there exists little agreement as to how to measure such effectiveness (Harris \& Kuhnert 2008; Shalhoop \& Sanger 2012). Lowe, Kroeck and Sivasubramaniam (1996) suggest two types of measures: (1) subordinate perceptions and (2) organisational measures. Whilst some authors (e.g. Hansbrough, Lord \& Schyns 2015) highlight concerns, such as common method bias, in using follower ratings, others (including Hogan \& Hogan 2001; Kang \& Jin 2015) argue that employee assessments are the best manner through which a leader can be evaluated. This research addresses subordinate perceptions of leadership effectiveness.

Perceptions of this type of effectiveness are influenced by leadership styles (Weaver 2015). These may be defined as 'the relatively consistent pattern of behavior that characterizes a leader' 
(DuBrin 2016:518). Although a myriad of such styles exist (Widder, Kolthoff \& Brindley 2016), Pearce et al. (2003:273), by means of an analysis of the leadership literature, offered a leadership typology comprising 'four theoretical behavorial types', being transactional, transformational, empowering and directive leadership. Both Houghton and Yoho (2005) and Ramthun and Matkin (2012) draw attention to the value of this typology by pointing out that it has been employed by a number of scholars as a foundation upon which to conceptualise various leadership models. Whilst the transactional and transformational styles occupy prominence in current leadership literature (Clark \& Waldron 2016; Sims, Faraj \& Yun 2009), empowering and directive leadership have attracted considerably less focus (Kalaluhi 2013; Sharma \& Kirkman 2015). There has also been some criticism in the literature as to the distinction between those behaviours that load onto transactional and transformational leadership as a result of factor analyses (Yukl 1999). This study therefore concentrated exclusively on empowering and directive leadership.

Leadership styles are culturally contingent (Bass \& Bass 2008; House et al. 2002; Paulienè 2012; Rockstuhl et al. 2011) as are perceptions of their respective effectiveness (Eckert et al. 2010; Holt, Bjorklund \& Green 2009; Jogulu 2010; Yan \& Hunt 2005). Based on their work, Martin, Liao and Campbell (2013) draw attention to the necessity of leaders modifying their behaviours, given subordinates' perceptions thereof. Hendrickson (2016) asserts that leaders who disregard culture, particularly during intercultural interactions, will adversely impact the effectiveness of their leadership. Conversely, leaders who are culturally cognisant and behave in accordance therewith are likely to be increasingly effective (Du Plessis 2011; Mustafa \& Lines 2012). With this in mind, Paulien (2012) indicates that effective leadership in individualistic cultures is generally regarded as the action of producing superior financial results. The focus is on the outcomes flowing from the behaviour of the leader as opposed to any specific behaviour type per se (Pauliene 2012). Collectivist societies, on the other hand, consider effective leadership as a durable objective germinating from subordinate dependability, which stems from leaders affording them security and direction (Pauliene 2012).

Cultural differences are accordingly a central situational influence in leadership effectiveness (Avery 2004; Deng \& Gibson 2008; Ersoy 2014). The inference is that leaders, in the adoption and display of leadership styles, need to be informed by the cultural predilections of their subordinates. This is especially relevant given the extent to which the workforce is now multicultural in nature (Balter, Chow \& Jin 2014; Kapur \& Janakiram 2015; Kodwani 2012; Raguž, Filipović \& Matijević 2014; Strydom \& Van Eeden 2013) as well as the shortage of effective multicultural leaders (Grubb 2014).

Whilst Jogulu (2010) argues that being amenable towards cultural sensitivities that could be profoundly dissimilar from one's own values and dogmas is essential for leadership effectiveness and Egel and Fry (2016) maintain that leaders must grasp varied cultural perspectives, Ayman and Korabik (2010) go a step further in submitting that to be effective, leaders must cultivate a multicultural mindset. Hence, ethnocentrism, defined as 'the view of things in which one's own group is the center of everything, and all others are scaled and rated with reference to it' (Sumner 1906:13), may inhibit the effectiveness of leadership (Kumar, Anjum \& Sinha 2011; Northouse 2013); that is, leader actions that are incongruent with essential follower values arouse adverse sentiments (Mustafa \& Lines 2012). Specifically, leaders' ethnocentric tendencies may have a toxic effect on their relationship with subordinates (Caligiuri \& Tarique 2012).

The need for leadership that is able to navigate effectively across diverse cultures is therefore both exigent and extensive (Groves \& Feyerherm 2011; Ko 2015; Lovvorn \& Chen 2011; Manning 2003). Alon et al. (2016) point out that effective leadership is founded upon multiple intelligence types, one of which is cultural intelligence (CQ) - or 'a person's capacity to adapt to new cultural settings' (Earley 2002:271). It has been suggested that CQ may contribute to overcoming ethnocentrism (Caldwell 2015; Triandis 2006) and, to this end, Harrison (2012) found a negative correlation between ethnocentrism and CQ. Livermore and Ang (2016) argue that CQ is a trustworthy forecaster of one's effectiveness, whereas Oliverio-Olivieri (2016) maintains that leaders who are effective exhibit CQ. Ng, Van Dyne and Ang (2012) refer to the role that CQ plays in improving leadership effectiveness. It is reasonable then to expect that CQ will assist leaders to fare better, that is, to be increasingly effective when operating within culturally heterogeneous situations.

Empirical evidence of the relationship between leader CQ and leadership effectiveness is sparse in that just a handful of studies have specifically examined the association between these two concepts. Deng and Gibson (2008) as well as Ersoy (2014) found, in their respective qualitative studies, that leader CQ positively impacted the effectiveness of leaders. Research by Groves and Feyerherm (2011), based on data obtained from 99 leaders and 321 of their subordinates, indicated that leader CQ predicted leadership effectiveness. The study by Rockstuhl et al. (2011) of 126 Swiss military officers established that leader CQ was positively related to the effectiveness of cross-border leadership, yet demonstrated no relationship with general leadership effectiveness. Musamali and Martin (2016) investigated the association between five separate effective leadership practices and the dimensions of CQ in higher education institutions in Kenya and the United States. They found that, at the 5\% significance level, cognitive CQ correlated significantly with three of the practices, whilst metacognitive CQ and motivational CQ each displayed a significant correlation with one of the practices. Behavioural CQ did not correlate with any of the practices.

The above-mentioned dearth of empirical insights is exacerbated when leadership style is introduced as a variable. As Presbitero (2016) observes, CQ can play the role of 
moderator in the relationship between two variables and, since the authors of this article are not aware of efforts to specifically examine CQ as the moderator between leadership style and leadership effectiveness, they, through this study, aimed to address such paucity in the knowledge base.

\section{Research purpose}

The purpose of this research was to determine whether leader CQ affected the relationship between leadership style (empowering and directive) and leadership effectiveness.

\section{Research question}

The question that directed this study was: Is the relationship between leadership style (empowering and directive) and leadership effectiveness moderated by leader CQ?

\section{Literature review}

The aim of the literature review was to introduce and describe the concepts forming part of the study.

\section{Cultural intelligence}

CQ is 'an individual's capability to adapt effectively to situations of cultural diversity' (Earley \& Ang 2003:3) and, hence, depicts the capacity to seamlessly make the transition across multiple cultures as opposed to just a single or few cultures (Ng et al. 2012). CQ thus allows for the alleviation of stresses that emerge as a result of heightened exchanges between those persons possessing divergent cultural identities (Jonck \& Swanepoel 2015).

CQ persists as a discrete form of intelligence (Du Plessis 2011) in that it may be distinguished from general cognitive intellect as well as emotional intelligence (Ang, Van Dyne \& Rockstuhl 2015). Whereas general cognitive intellect reflects the cognitive placement of intellectual aptitude (Bovornusvakool, Ardichvili \& Rana 2015) and emotional intelligence depicts the capacity to recognise and control emotions, neither includes the capability to interact with persons representative of cultural diversity ( $\mathrm{Ng}$ et al. 2012).

CQ is multi-dimensional in nature (Ang et al. 2007). The dimensions comprise (1) metacognition, which refers to 'thought processes' (Racicot \& Ferry 2016:116), that is, the ability of leaders to prepare optimally for cross-cultural interaction, to assess progress during the exchange and to effect any modifications to their mental framework regarding the other culture (Van Dyne, Ang \& Livermore 2010); (2) cognition, which refers to cultural knowledge, as reflected by standards and practices (Ang et al. 2007) relating to linguistics, religious views, social behaviours as well as monetary and legal processes (Van Dyne, Ang \& Nielsen 2008b) and, as such, represents the extent to which a leader grasps the concept of culture and the part it plays in directing crosscultural interactions (Van Dyne et al. 2010); (3) motivation, which concerns the desire to participate in intercultural exchanges (Ang et al. 2015) or the efforts leaders expend in adapting cross-culturally (Van Dyne et al. 2010) and which evidences their intrinsic belief that they can operate fruitfully in intercultural conditions (Van Dyne et al. 2008b) and (4) behaviour, which refers to overt actions $(\mathrm{Ng}$, Van Dyne \& Ang 2009) that are culturally pertinent (Sutherland, Edgar \& Duncan 2015) and may be verbal or non-verbal (Ang et al. 2015). Metacognitive and cognitive CQ represent the intellectual component of CQ and, hence, assist in developing the perspectives that flow from varied cultural experiences, whilst the action imperative is embodied in motivational and behavioural CQ (Mannor 2008).

\section{Empowering and directive leadership}

Empowering and directive leadership represent distinct and dissimilar leadership behaviours (Hmieleski \& Ensley 2007) and are, thus, situated at the opposite ends of a range based on the extent to which subordinates are able to exert control (Clark, Hartline \& Jones 2009). Fong and Snape (2015) point out that organisations are evolving from a penchant for hierarchical leadership to one in which leaders encourage employee empowerment and support. Empowering leadership promotes 'self-leadership, participative goalsetting, and opportunity thinking by followers' (Ling et al. 2015:1067). As such, empowering leadership consists of employees perceiving that their leader's actions facilitate their involvement in decision-making through the provision of opportunities for thinking innovatively and thereby taking measured risks (Bester, Stander \& Van Zyl 2015). Accordingly, empowering leadership stimulates responsibility taking as opposed to the issuing of instructions (Maggitti, Slay \& Clark 2010) and is, in the main, distinguishable from other styles of leadership in that it eliminates subordinates' feelings of powerlessness (Li et al. 2016). Clark and Waldron (2016) observe that this style of leadership also promotes sharing and cooperation.

Empowering leadership has been demonstrated to be an 'effective leadership style for many employees and organizational settings' (Sharma \& Kirkman 2015:199). With this in mind, Sharma and Kirkman (2015) note that empowering leadership has been positively linked with both (1) organisational and team outcomes (incorporating: performance, behaviours, efficacy and knowledge creation) and (2) individual level results (such as positive employee attitudes, engagement, satisfaction, creativity, employee inand extra-role behaviours, knowledge sharing and follower commitment). Indeed, Praszkier (2015:34) considers that empowering leadership 'is becoming critical in the growing world of multiplicity and unpredictability'.

However, a number of scholars (including, Cheong et al. 2016; Wong \& Giessner 2016; Yun, Cox \& Sims 2006) have established that where subordinate expectations of empowerment are not aligned with leader empowering behaviours, empowerment can have adverse consequences. Lee et al. (2016) found that a curvilinear relationship (an inverted U shape) exists between empowering leadership and employee task performance. This suggests that a point is 
reached where additional empowerment actually begins to detract from an employee's performance despite him or her being inclined to such a leadership style. It is not irrational to expect the effectiveness of this leadership style to diminish following poor staff member performance.

Directive leadership entails providing subordinates with precise guidance on what needs to be achieved, how it should be done and the necessary quality level (Martin et al. 2013), and appears to be more prevalent among lower level leaders as opposed to their more senior counterparts (Oshagbemi 2008). Directive leaders observe performance and provide comment thereon (Martin et al. 2013) whilst making use of chastisement when goals are not achieved (Clark \& Waldron 2016). This leadership style is optimal when a leader exercises legitimate power and the work activities of subordinates are organised, logical and do not involve complexity (Sauer 2011).

Directive leadership has been associated with poor decisionmaking (Cruz, Henningsen \& Smith 1999) and has been deemed less attractive than empowering leadership (Lorinkova, Pearsall \& Sims 2013). Nonetheless, directive leadership is noted as assisting in the evolution of a vision shared by non-homogeneous senior management teams (Hmieleski \& Ensley 2007). It promotes proactive employee behaviours when employees are satisfied with their leader (Martin et al. 2013). This leadership style has also been found to enhance the relationship between transformational leadership and organisational commitment (Mesu, Sanders \& Van Riemsdijk 2015). It delivers initial team performance faster than that achieved in teams with empowering leaders (Lorinkova et al. 2013) and is the appropriate leadership style when staff members have an external locus of control (Mittal 2015) or a major crisis is faced (Maggitti et al. 2010).

Despite the absence of empirical outputs on the relationship between CQ and each of empowering and directive leadership, Livermore (2015) contends that culturally intelligent leaders are able to discern the requirement for an empowering style rather than one based upon providing direction. This is vital as Martin et al. (2013:1386) found in their study that empowering and directive leadership could be 'equifinal' (i.e. achieve the same end result) in delivering core task proficiency.

\section{Leadership effectiveness}

Leadership effectiveness represents the ability of a leader 'to mobilize and influence followers' (Cicero, Pierro \& Van Knippenberg 2010:411) and is crucial in that it drives the proclivity of the workforce towards the attainment of shared goals (De Cremer \& Van Knippenberg 2004). In this respect, Manamela, Cassim and Karodia (2016) observe that effective leaders are adept at recognising and positively utilising both the competencies and limitations of their subordinates in the achievement of organisational objectives. Weaver (2015) likewise affirms the constructive impact that effective leaders have on the results of their subordinates.
Dorfman et al. (2012) comment that leaders who act in accordance with expectations are the most effective, whilst Bjurstedt (2007) insists that effective leaders are those who favour personal over positional power and are also able to adjust their style as required. Manning (2003:21) notes that leaders effective in cross-cultural leadership possess 'relationship competence': that is, they are able to emotionally connect with diverse individuals and establish mutually attractive relationships.

It appears then that effective leaders are those who exemplify interpersonal aptitudes that allow them to form solid connections with an array of individuals through which they add value to the latter in accordance with expectations which, in turn, leads to goal accomplishment.

Leadership effectiveness may be evaluated in a variety of ways and at different levels (Kang \& Jin 2015). Kaiser, Hogan and Craig (2008), through an examination of 10 metaanalyses, identified two primary measurement types for leadership: (1) individual perceptions and (2) group performance (these two measurement groupings are similar to those noted by Lowe et al. 1996, and mentioned earlier in this article). Individual perceptions may be split between (1) leadership emergence (being perceived as a leader by, for example, colleagues) and (2) perceived effectiveness (as a leader) (Kaiser et al. 2008). Group performance comprises (1) group process (results achieved in terms of team member motivation, behaviour levels and team dynamics) and (2) group achievements such as productivity and financial outcomes (Kaiser et al. 2008). The effectiveness of leaders exhibits a greater alignment with subordinates' perspectives of leader actions, as opposed to leaders' self-reported views (Kim \& Yukl 1995). Likewise, Conway (2000) notes that subordinates' ratings may offer an enhanced reflection of the aptness of leader behaviours.

Leadership effectiveness has been linked with leader intelligence (Mesterova et al. 2015) and is associated with leader self-awareness (Butler, Kwantes \& Boglarsky 2014). It may be predicted by leader prototypicality (especially where subordinates are subject to role ambiguity) (Cicero et al. 2010). It is also influenced by the quality of the exchange relationships between leaders and each of their subordinates (Alabi 2012) (see Kim, Liu \& Diefendorff 2015 for a discussion of Leader-Member Exchange) and is positively related to organisational cultures that endorse employee satisfaction (Kwantes \& Boglarsky 2007). In terms of leadership styles, perceptions of leadership effectiveness correlate with transformational and transactional (Deluga 1991) as well as empowering and ethical leadership (Hassan et al. 2013).

\section{Hypotheses}

The hypotheses investigated were as follows:

- $\mathrm{H} 1_{0}$ : The CQ of leaders (as a composite concept) does not moderate the relationship between leaders' application of empowering leadership and employee perceptions of their leadership effectiveness. 
- $\mathrm{H}_{0}$ : The CQ dimensions of leaders do not moderate the relationship between leaders' application of empowering leadership and employee perceptions of their leadership effectiveness.

- $\mathrm{H}_{0}$ : The CQ of leaders (as a composite concept) does not moderate the relationship between leaders' application of directive leadership and employee perceptions of their leadership effectiveness.

- $\mathrm{H} 4_{0}$ : The CQ dimensions of leaders do not moderate the relationship between leaders' application of directive leadership and employee perceptions of their leadership effectiveness.

\section{Research method}

This section sets out applicable methodological details as a basis for contextualising the research that was undertaken.

\section{Research design}

A cross-sectional survey design was employed. This design is useful when the intention is to examine a population in terms of particular outcomes (Levin 2006).

\section{Population}

The population was defined as all leaders, irrespective of their level of seniority or particular function, at all organisations operating in South Africa. A leader was considered to be any employee to whom another staff member directly reports.

\section{Sample}

Without an entrée into an organisation, it is frequently difficult to obtain permission to approach employees with a view to undertaking research. Hence, a convenience sample was drawn from 19 South African organisations. Access to the organisations was achieved by recruiting 18 master's degree level students (the students), from the Graduate School of Business Leadership at the University of South Africa (GSBL), to act as fellow researchers; they were employed by the respective organisations. The 19th organisation that participated was the employer of the first named author.

Most CQ research to date has been based upon self-report methodologies; as a result the application of observer originated measures could enhance the strength of $C Q$ research findings (Ang et al. 2015). Similarly, as noted earlier, Conway (2000) and Kim and Yukl (1995) highlight the benefits of using subordinates to evaluate leaders. Sample respondents thus consisted of the subordinates of leaders. In total, 1140 completed responses to the survey were received.

\section{Unit of analysis}

Staff members' perceptions of their leaders' CQ, leadership style and leadership effectiveness comprised the individual unit of analysis.

\section{Survey questionnaire}

A number of instruments, which are described in the sections below, were included in the survey questionnaire in order to measure the study variables.

\section{Leader cultural intelligence}

Leader CQ was assessed via the observer report version of the Cultural Intelligence Scale (CQS) (Van Dyne, Ang \& Koh 2008a). The CQS has demonstrated all types of validity: convergent, criterion and discriminant (Van Dyne et al. 2008a) and has been shown to be reliable (Rockstuhl et al. 2011).

\section{Empowering leadership}

Empowering leadership was measured by the 10-item instrument of Ahearne, Mathieu and Rapp (2005). Zhang and Bartol (2010) indicate that it captures the essence of empowering leadership, whilst Yoon (2012) confirmed the validity of this instrument.

\section{Directive leadership}

Directive leadership was evaluated by a combination of the six- and four-item instruments of Pearce and Sims (2002) and Hwang et al. (2015), respectively. The reliability of the instruments' items has been confirmed by Hinrichs (2011) and Hwang et al. (2015), respectively.

\section{Leadership effectiveness}

Leadership effectiveness was measured through four items constructed by Cicero et al. (2010). These items have delivered a high level of reliability (Cicero et al. 2010).

Permission to use the instruments was obtained from the respective authors.

\section{Research process}

The research process commenced with an application for ethical clearance from the Research Ethics Review Committee of the GSBL. Once such approval had been secured (under no: 2016_SBL_003_CA), the students attended a session at which further details of the research were discussed. In particular, they were exposed to the survey questionnaire and the respondent information sheet, concepts were explained and timelines agreed. The students were provided with a template that they were required to have completed by their respective employer's chief executive in terms of which permission was granted, on the basis of the organisation's anonymity, for the research to be conducted therein.

After consent had been obtained from the chief executive of their respective employer, the students sourced a list of employees from the human resource division of their organisation and allocated a number to each name. Potential respondents were identified randomly through the application of a random number generator. The students 
then invited the identified persons to a meeting at which the research was explained. They were also advised that participation would be on a purely voluntary basis. It was pointed out that neither they nor the organisation would be required to disclose any identifying particulars.

Attendees were subsequently provided with a research information sheet. Those staff members who indicated their willingness to participate were handed a hard copy of the questionnaire and were requested to complete it at the meeting. The data from the completed questionnaires were then entered into a template-based spreadsheet by the students and submitted to the second named author. The first named author followed the same process in administering the questionnaire to respondents from his employer. The second named author consolidated the 19 spreadsheets received.

\section{Data analysis}

Data analysis was conducted through IBM SPSS. Respondent demographics were established by calculating frequencies and certain central statistics. Central statistics were also computed for the independent and dependent variables. These included minimum and maximum values, mean scores as well as standard deviations.

Relationships between variables were evaluated through the calculation of Pearson's product-moment correlation coefficients. Statistical significance was evaluated at the 5\% level, as recommended by Lazaraton (1991). The practical significance of correlation was determined with respect to the guidelines devised by Cohen (1988), which indicate that correlations are small when they fall between 0.10 and 0.30 , medium when they lie between 0.30 and 0.50 and are large when they exceed 0.50 .

Principal axis factor analysis with direct Oblimin rotation was employed to assess instrument validity. The guidelines suggested by Coovert and McNelis (1988) and Costello and Osborne (2005) were followed in determining the number of factors to retain; that is, factors with eigenvalues exceeding 1 and scree plot examination, respectively.

In examining the scree plots, the number of factors to keep was taken to be the number of eigenvalues that preceded the final main drop in extent (DeCoster 1998) or 'the point at which the slope approaches zero' (Floyd \& Widaman 1995:292). The recommendation by Osborne and Costello (2009:138) that a 'solid factor' is one which has ' 5 or more strongly loading items ( 0.50 or better)' was followed in assessing factor desirability. Osborne and Costello (2009) also suggest that a weak factor is one that has less than three items loading on it. Thus, a factor was accepted where it had no fewer than four items, or at least $80 \%$ of the number of items from the respective measurement scale, that loaded onto it with a minimum weight of 0.50 (Hair et al. 2010). Reliability was assessed as acceptable where Cronbach's coefficient alphas were greater than 0.70 (see Pallent 2011).
To test for moderation, a two-step approach, as suggested by Garnett, Marlowe and Pandey (2008), was adopted. These steps entail (1) confirmation that both the independent and moderator variables relate at a statistically significant level to the dependent variable and (2) calculation of the relationships again together with the inclusion of an interaction term (representing a combination of the independent and moderator variables). Where the results of the second calculation show evidence of a statistically significant relationship between the interaction term and the dependent variable, then the variation between the effect of the independent variable in the first and second calculations may be attributed to the presence of the moderator variable (Garnett et al. 2008).

The practical significance of the regression model's moderation was appraised through the calculation of the $f^{2}$ statistic. This statistic, note Ellis and Steyn (2003), acts as a measure of the effect size in multiple regressions and is calculated as $R^{2} /\left(1-R^{2}\right)$.

Where $R^{2}<0.13, f^{2}$ will be under 0.15 . In such instances it may be accepted that $R^{2}$ does not, practically, differ from zero and the size of the regression coefficient is therefore not significant at a practical level (Ellis \& Steyn 2003). On the other hand, Ellis and Steyn (2003) conclude, from the guidelines by Cohen (1988), that where $f^{2}$ exceeds 0.35 , the effect of $R^{2}$ is of practical importance. For this study, an $f^{2}$ under 0.15 was deemed as not significant, as medium when it was situated between 0.15 and 0.35 and as large when it exceeded 0.35 .

\section{Results}

The data analysis results appear below, starting with respondent demographics (Tables 1-3) and descriptive statistics of the variables (Table 4). The psychometric properties of the measures follow (Table 5). In turn, correlation (Table 6) and moderation statistics (Tables 7 and 8) are subsequently presented.

\begin{tabular}{lccc} 
TABLE 1: Gender. & & & \\
\hline Gender & Frequency & \% & Cumulative $\%$ \\
\hline Male & 573 & 50.27 & 50.27 \\
Female & 567 & 49.73 & 100.00 \\
\hline Total & $\mathbf{1 1 4 0}$ & $\mathbf{1 0 0 . 0 0}$ & - \\
\hline
\end{tabular}

Source: Authors' own work

TABLE 2: Age (years).

\begin{tabular}{lcccc}
\hline Youngest & Oldest & Mean & Median & Standard deviation \\
\hline 20 & 64 & 38.62 & 37.00 & 9.36 \\
\hline
\end{tabular}

Source: Authors' own work

TABLE 3: Race.

\begin{tabular}{lccc}
\hline Race & Frequency & $\mathbf{\%}$ & Cumulative $\%$ \\
\hline Black & 762 & 66.84 & 66.84 \\
White & 206 & 18.07 & 84.91 \\
Coloured & 116 & 10.18 & 95.09 \\
Asian & 56 & 4.91 & 100.00 \\
\hline Total & $\mathbf{1 1 4 0}$ & $\mathbf{1 0 0 . 0 0}$ & - \\
\hline
\end{tabular}

Source: Authors' own work 
TABLE 4: Descriptive statistics.

\begin{tabular}{|c|c|c|c|c|}
\hline Variable & Minimum & Maximum & Mean & Standard deviation \\
\hline Leader CQ aggregate & 1.00 & 7.00 & 4.53 & 1.17 \\
\hline Leader metacognitive CQ & 1.00 & 7.00 & 4.96 & 1.45 \\
\hline Leader cognitive CQ & 1.00 & 7.00 & 4.42 & 1.33 \\
\hline Leader motivational CQ & 1.00 & 7.00 & 4.57 & 1.34 \\
\hline Leader behavioural CQ & 1.00 & 7.00 & 4.15 & 1.40 \\
\hline Empowering leadership & 1.00 & 7.00 & 5.12 & 1.37 \\
\hline Directive leadership & 1.00 & 5.00 & 3.52 & 0.81 \\
\hline Leadership effectiveness & 1.00 & 7.00 & 5.08 & 1.69 \\
\hline
\end{tabular}

Source: Authors' own work

$\mathrm{CQ}$, cultural intelligence.

TABLE 5: Factor analysis and reliability information.

\begin{tabular}{|c|c|c|c|c|c|}
\hline \multirow[t]{2}{*}{ Variable } & \multicolumn{4}{|c|}{ Validity information (factorial validity) } & \multirow{2}{*}{$\begin{array}{c}\text { Reliability } \\
\text { Coefficient } \alpha\end{array}$} \\
\hline & Kaiser-Meyer-Olkin scores & Bartlett's test of sphericity & No. of factors & Percent of variance declared & \\
\hline Leader CQ aggregate & 0.95 & $17980.20 *$ & 4 & 74.38 & 0.95 \\
\hline Leader metacognitive $\mathrm{CQ}$ & - & - & - & - & 0.93 \\
\hline Leader cognitive CQ & - & - & - & - & 0.91 \\
\hline Leader motivational CQ & - & - & - & - & 0.90 \\
\hline Leader behavioural CQ & - & - & - & - & 0.91 \\
\hline Directive leadership & 0.84 & $6434.06 *$ & 3 & 75.90 & 0.87 \\
\hline Leadership effectiveness & 0.86 & 4723.18* & 1 & 87.13 & 0.95 \\
\hline
\end{tabular}

Source: Authors' own work

$\mathrm{CQ}$, cultural intelligence.

$*, p<0.05$.

\section{TABLE 6: Correlations.}

\begin{tabular}{|c|c|c|c|c|c|c|c|c|}
\hline Variable & 1 & 2 & 3 & 4 & 5 & 6 & 7 & 8 \\
\hline 1. Leader CQ aggregate & - & - & - & - & - & - & - & - \\
\hline 2. Leader metacognitive $\mathrm{CQ}$ & $0.85 *$ & - & - & - & - & - & - & - \\
\hline 3. Leader cognitive $\mathrm{CQ}$ & $0.86 *$ & $0.64 *$ & - & - & - & - & - & - \\
\hline 4. Leader motivational CQ & $0.88 *$ & $0.66 *$ & $0.72 *$ & - & - & - & - & - \\
\hline 5. Leader behavioural CQ & $0.81 *$ & $0.56^{*}$ & $0.58 *$ & $0.62 *$ & - & - & - & - \\
\hline 6. Empowering leadership & $0.64 *$ & $0.64 *$ & $0.49 *$ & $0.57^{*}$ & $0.45^{*}$ & - & - & - \\
\hline 8. Leadership effectiveness & $0.59 *$ & $0.61 *$ & $0.48 *$ & $0.52 *$ & $0.41 *$ & $0.77 *$ & $0.47^{*}$ & - \\
\hline
\end{tabular}

Source: Authors' own work

$\mathrm{CQ}$, cultural intelligence.

$*, p<0.05$.

\section{Respondent demographics}

The genders were evenly spread. This compares favourably with South African workforce gender statistics (see Statistics South Africa 2016) which reflect men as comprising 56.25\% and women as $43.75 \%$ of this force.

The oldest respondent was 64 whereas the youngest was 20 . The median age of the sample was 37 .

Black and White dominated race group representation. This is largely reflective of the South African working population profile estimates (see Statistics South Africa 2016) where Black made up $73.38 \%$, White $12.71 \%$, mixed race $10.67 \%$ and Asian 3.24\% of employed persons.

\section{Descriptive statistics}

It can be perceived from Table 4 that leader CQ (aggregate) achieved a mean score of 4.53 . At a dimensional level, leader metacognitive CQ scored the highest (4.96) whilst leader behavioural CQ was rated the lowest (4.15). The mean score for empowering leadership was 5.12 whilst it was 3.52 for directive leadership. The lower mean score for directive leadership could be due to the respective rating scale ranging from 1 to 5. Leadership effectiveness was rated at 5.08.

\section{Psychometric properties of the measures Reliability}

Reliabilities were assessed as satisfactory because all the alphas exceeded 0.70 (see Table 5). In fact all the alphas, with the exception of that for directive leadership, were 0.90 or greater. Leader CQ in aggregate as well as leadership effectiveness achieved the highest alphas (0.95). The lowest alpha was 0.87 (for directive leadership).

\section{Factorial validity}

All of the study variables were found to be factorable, whilst sampling adequacy was acceptable based on Kaiser-MeyerOlkin scores (see Dziuban \& Shirkey 1974, for guidelines) 
TABLE 7: Moderated multiple regression - Empowering leadership and leadership effectiveness.

\begin{tabular}{|c|c|c|c|c|c|c|c|}
\hline Variable & $R$ & $R^{2}$ & $R^{2}$ change & Coefficients & Standard error & $t$ & $p$ \\
\hline Model 1 & 0.780 & 0.609 & - & - & - & - & - \\
\hline Constant & - & - & - & 5.08 & 0.04 & 131.98 & $0.00 *$ \\
\hline Leader CQ aggregate & - & - & - & 0.25 & 0.04 & 6.63 & $0.00 *$ \\
\hline Empowering leadership & - & - & - & 0.81 & 0.03 & 23.69 & $0.00 *$ \\
\hline Interaction term & - & - & 0.00 & -0.01 & 0.02 & -0.19 & 0.85 \\
\hline Model 2 & 0.782 & 0.612 & - & - & - & - & - \\
\hline Leader metacognitive $\mathrm{CQ}$ & - & - & - & 0.22 & 0.03 & 7.20 & $0.00^{*}$ \\
\hline Empowering leadership & - & - & - & 0.79 & 0.04 & 22.51 & $0.00 *$ \\
\hline Interaction term & - & - & 0.00 & -0.01 & 0.02 & -0.51 & 0.61 \\
\hline Model 3 & 0.777 & 0.604 & - & - & - & - & - \\
\hline Constant & - & - & - & 5.08 & 0.04 & 145.34 & $0.00 *$ \\
\hline Leader cognitive $\mathrm{CQ}$ & - & - & - & 0.17 & 0.03 & 6.10 & $0.00 *$ \\
\hline Empowering leadership & - & - & - & 0.87 & 0.03 & 30.64 & $0.00 *$ \\
\hline Model 4 & 0.774 & 0.600 & - & - & - & - & - \\
\hline Constant & - & - & - & 5.08 & 0.04 & 135.10 & $0.00 *$ \\
\hline Leader motivational CQ & - & - & - & 0.15 & 0.03 & 4.68 & $0.00 *$ \\
\hline Empowering leadership & - & - & - & 0.87 & 0.03 & 27.05 & $0.00 *$ \\
\hline Interaction term & - & - & 0.00 & 0.00 & 0.02 & -0.03 & 0.98 \\
\hline Model 5 & 0.772 & 0.595 & - & - & - & - & - \\
\hline Constant & - & - & - & 5.07 & 0.04 & 142.15 & $0.00 *$ \\
\hline Leader behavioural CQ & - & - & - & 0.09 & 0.03 & 3.25 & $0.00 *$ \\
\hline Empowering leadership & - & - & - & 0.91 & 0.03 & 31.08 & $0.00 *$ \\
\hline Interaction term & - & - & 0.00 & 0.01 & 0.02 & 0.69 & 0.49 \\
\hline
\end{tabular}

Source: Authors' own work

$\mathrm{CQ}$, cultural intelligence.

$*, p<0.05$.

TABLE 8: Moderated multiple regression - Directive leadership and leadership effectiveness.

\begin{tabular}{|c|c|c|c|c|c|c|c|}
\hline Variables & $R$ & $R^{2}$ & $R^{2}$ change & Coefficients & Standard error & $t$ & $p$ \\
\hline Model 1 & 0.654 & 0.428 & - & - & - & - & - \\
\hline Constant & - & - & - & 5.13 & 0.04 & 121.65 & $0.00 *$ \\
\hline Leader CQ aggregate & - & - & - & 0.68 & 0.04 & 16.08 & $0.00 *$ \\
\hline Directive leadership & - & - & - & 0.54 & 0.06 & 9.06 & $0.00 *$ \\
\hline Interaction term & - & - & 0.009 & -0.15 & 0.03 & -4.34 & $0.00 *$ \\
\hline Model 2 & 0.675 & 0.456 & - & - & - & - & - \\
\hline Constant & - & - & - & 5.11 & 0.04 & 124.69 & $0.00 *$ \\
\hline Leader metacognitive CQ & - & - & - & 0.58 & 0.03 & 17.69 & $0.00 *$ \\
\hline Directive leadership & - & - & - & 0.62 & 0.06 & 10.54 & $0.00 *$ \\
\hline Interaction term & - & - & 0.004 & -0.08 & 0.03 & -2.57 & $0.01 *$ \\
\hline Model 3 & 0.582 & 0.339 & - & - & - & - & - \\
\hline Constant & - & - & - & 5.12 & 0.04 & 114.48 & $0.00 *$ \\
\hline Leader cognitive CQ & - & - & - & 0.44 & 0.04 & 12.21 & $0.00 *$ \\
\hline Directive leadership & - & - & - & 0.69 & 0.06 & 10.78 & $0.00 *$ \\
\hline Interaction term & - & - & 0.008 & -0.12 & 0.04 & -3.34 & $0.00 *$ \\
\hline Model 4 & 0.610 & 0.372 & - & - & - & - & - \\
\hline Constant & - & - & - & 5.14 & 0.04 & 117.25 & $0.00 *$ \\
\hline Leader motivational CQ & - & - & - & 0.49 & 0.04 & 12.99 & $0.00 *$ \\
\hline Directive leadership & - & - & - & 0.63 & 0.06 & 10.33 & $0.00^{*}$ \\
\hline Interaction term & - & - & 0.012 & -0.15 & 0.03 & -4.77 & $0.00 *$ \\
\hline Model 5 & 0.553 & 0.306 & - & - & - & - & - \\
\hline Constant & - & - & - & 5.11 & 0.04 & 115.98 & $0.00 *$ \\
\hline Leader behavioural CQ & - & - & - & 0.36 & 0.03 & 10.50 & $0.00 *$ \\
\hline Directive leadership & - & - & - & 0.77 & 0.06 & 12.35 & $0.00 *$ \\
\hline Interaction term & - & - & 0.006 & -0.10 & 0.03 & -3.05 & $0.00 *$ \\
\hline
\end{tabular}

Source: Authors' own work

$\mathrm{CQ}$, cultural intelligence.

$*, p<0.05$.

and the significance of the Bartlett's Tests of Sphericity (see Table 5). Applying the eigenvalue rule of greater than 1 and confirming this with the number of eigenvalues that were located prior to the final drop in magnitude per scree plots, leader CQ was assessed as having four factors with a declared variance of $74.38 \%$. Directive leadership was found to have 
three factors with a declared variance of $75.90 \%$. These factors exhibited high internal consistency in that the alpha did not rise when scale items were purged. Thus, for purposes of this study, directive leadership was accepted as unidimensional. Empowering leadership and leadership effectiveness had one factor each. The declared variance for empowering leadership was $62.16 \%$ whilst it was $87.13 \%$ for leadership effectiveness. The number of items and their individual loadings for all the factors satisfied the guidelines as per Hair et al. (2010) and Osborne and Costello (2009) (discussed as part of the data analysis section).

\section{Correlations}

The correlation coefficients between leader CQ and each of its dimensions with leadership effectiveness ranged from a high of 0.61 in the case of metacognitive CQ to a low of 0.41 for behavioural CQ. Empowering leadership demonstrated a higher correlation with leadership effectiveness than did directive leadership (0.77 vs. 0.47$)$. All the correlations were statistically significant at the $5 \%$ level.

\section{Moderated multiple regressions}

Tables 7 and 8 present the results of the moderated multiple regressions that were performed to establish whether leader $\mathrm{CQ}$ and its dimensions influenced the relationship between empowering leadership and leadership effectiveness as well as that between directive leadership and leadership effectiveness.

As can be observed from table 7, the failure of the interaction terms to achieve statistical significance indicated that neither leader $C Q$, as an aggregate value, nor any of its individual dimensions displayed a moderator effect on the relationship between empowering leadership and leadership effectiveness. Thus, $\mathrm{H}_{0}$ and $\mathrm{H}_{2}$ were not rejected.

Table 8 demonstrates that leader CQ as well as its four dimensions did exhibit a statistically significant moderation effect on the relationship between directive leadership and leadership effectiveness. Hence, both $\mathrm{H}_{0}$ and $\mathrm{H}_{0}$ were rejected.

Figure 1 displays the absence of moderation by aggregate leader CQ on the relationship between empowering leadership and leadership effectiveness. Figure 2 indicates that aggregate leader CQ moderated the relationship between directive leadership and leadership effectiveness. The influencing effects of the leader CQ dimensions were almost exactly the same as the aforementioned patterns and are therefore not presented here.

Figure 1 reveal that the intercepts for the three levels of leader CQ are close to one another and that the slopes of the lines are essentially parallel. In this case, it can be noted that moderation did not take place. Figure 2 reflects, in contrast, that moderation did occur as the intercepts are

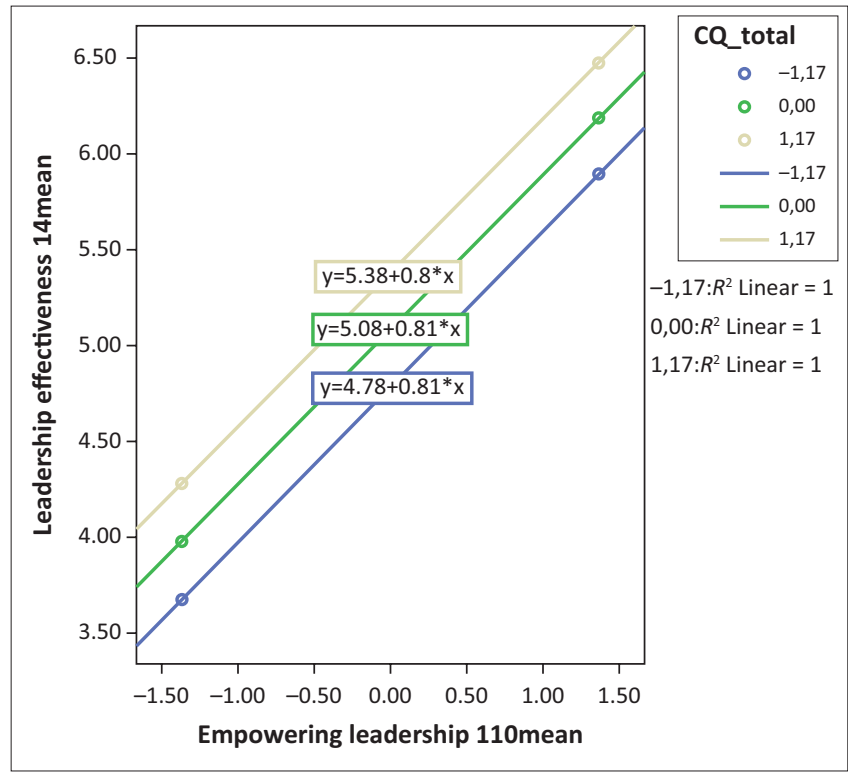

Source: Authors' own work

FIGURE 1: Leader cultural intelligence (aggregate) moderation on the relationship between empowering leadership and leadership effectiveness.

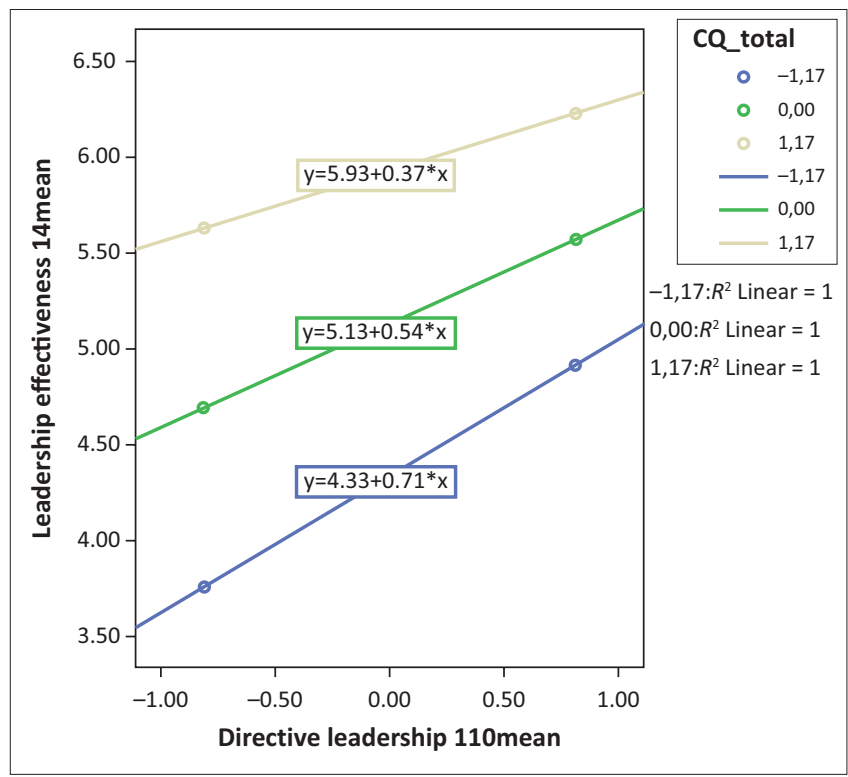

Source: Authors' own work

FIGURE 2: Leader cultural intelligence (aggregate) moderation on the relationship between directive leadership and leadership effectiveness.

further apart and the lines have non-parallel slopes. The slope of the line where leader CQ is low is steeper than that of the line where leader CQ is high. This suggests that the moderation effect is greater at lower, rather than higher, levels of leader CQ.

\section{Discussion}

The positive relationship that was found to exist between leader CQ and leadership effectiveness (given the different cultures of the respondents) is in line with the findings of Rockstuhl et al. (2011) that leader CQ was positively related to the effectiveness of cross-border leadership. The further finding that leader CQ acted as an important predictor of 
leadership effectiveness complements the results of Groves and Feyerherm (2011).

On a sub-scale level, the result that leader metacognitive, cognitive and motivational CQ shared statistically significant relationships with leadership effectiveness offers support for the results of Musamali and Martin (2016). The result that leader behavioural CQ also had a relationship of statistical significance with leadership effectiveness, nevertheless, contradicts what Musamali and Martin (2016) established with regard to leader behavioural CQ and leadership effectiveness.

This research also provides evidence that both empowering and directive leadership had a relationship with leadership effectiveness that carried statistical significance. The strength of these relationships was, however, much greater for empowering leadership than it was for directive leadership. Although there may be various explanations for this difference in strength, it is possible that it may have been a function of the cultural profiles of the respondents being of such a nature that they were more inclined towards empowering, as opposed to directive, leadership.

It is important to note that of the relationships identified in this study, just those between leader CQ in aggregate, metacognitive CQ, motivational CQ and empowering leadership with leadership effectiveness are significant at a practical level. Being moderate in nature, all the other relationships carried less real-world relevance.

Employing the methodology of Garnett et al. (2008) revealed that, whilst empowering leadership (as the independent variable) and leader CQ and its dimensions (as the respective moderator variables) did have, as noted previously, statistically significant relationships with leadership effectiveness (as the dependent variable), none of the interaction terms (i.e. empowering leadership multiplied by leader $C Q$ and empowering leadership multiplied by the $C Q$ dimensions) attracted statistical significance. As pointed out above, directive leadership (as the second independent variable) too, achieved a relationship of statistical significance with leadership effectiveness. In this case the effects of all the interaction terms (that is, directive leadership multiplied by leader CQ and directive leadership multiplied by the CQ dimensions) were statistically significant, implying moderation. The corresponding $t$-statistics were negative in all instances, indicating that a leader's CQ, and its dimensions, in fact served to reduce the strength of the relationship between directive leadership and leadership effectiveness.

As the respective changes in $R^{2}$ attributed to all the interaction terms were below 0.13 , it follows that none of the calculated $f^{2}$ statistics exceeded 0.15. Thus, the moderator effects of leader CQ and its dimensions on the relationship between directive leadership and leadership effectiveness were not significant from a practical perspective. (Note that practical significance was not considered in the case of empowering leadership and leadership effectiveness, as none of the observed effects for the interaction terms carried statistical importance.)

A possible reason why leader CQ and its dimensions did not moderate the relationship between empowering leadership and leadership effectiveness could be that those leaders who practice this style of leadership do so because they are culturally intelligent (as evidenced by the high correlation between leader CQ and empowering leadership). Similarly, it is conceivable that leader $C Q$, both in aggregate and dimensionally, moderated the relationship between directive leadership and leadership effectiveness because such leaders are viewed as being less culturally intelligent than their empowering counterparts (see Table 6). The negative direction of this moderation might be a signal that as directive leaders become increasingly culturally intelligent, they ought to realise a different leadership style would be more appropriate.

\section{Theoretical implications}

This research provides evidence for the four factor theoretical structure of CQ as conceptualised by Earley and Ang (2003). This result supports the findings of Mahembe and Engelbrecht (2014) who established the validity of the four CQ dimensions in their study of 229 full-time students at a South African university.

The CQ and leadership nomological networks have also been increased as it has been shown that leader $C Q$, including each of its dimensions, as well as empowering and directive leadership, all exhibited statistically significant associations with leadership effectiveness. Further, it was established that leader CQ and its dimensions did not influence the relationship between empowering leadership and leadership effectiveness and also that, whilst at a statistical level they did act as negative moderators of the relationship between directive leadership and leadership effectiveness, such moderation was actually of no practical consequence.

\section{Practical implications}

Taking account of the relative strength of the relationships between each of the leader CQ dimensions with leadership effectiveness, leaders are advised to direct attention to the development of their metacognitive CQ in particular. It would also be important for them to enhance their levels of motivational CQ as this was the CQ dimension that recorded the second strongest relationship with leadership effectiveness.

As subordinates perceived empowering leadership, rather than directive leadership, to be more strongly associated with leadership effectiveness, leaders, in general, should pursue an empowering style. However, leaders are advised to exercise caution in indiscriminately empowering subordinates in that some of them, given their particular cultures, may not embrace this approach (see Cheong et al. 2016; Wong \& Giessner 2016; Yun, Cox \& Sims 2006). 
Leaders should further note that neither their CQ nor any of its individual dimensions are important influencers of the relationships that the leadership styles (in this case empowering and directive leadership) had with leadership effectiveness. It is suggested that culturally intelligent leaders could be using their CQ to inform themselves concerning selecting a suitable style of leadership; that is, leader CQ (including its dimensions) may affect the choice of leadership style.

\section{Limitations and recommendations}

The first limitation of this study relates to the use of a convenience sample. The scope for generalisation of the findings to the target population as a whole may therefore be restricted. This limitation, however, was somewhat allayed by the fact that (1) the participating organisations represent numerous industry types and are of varying sizes and (2) respondents within each of the organisations were chosen randomly. A second limitation concerns the richness of the insights in that these could have been amplified had a mixed methods approach been used. Finally, collecting leader CQ and leadership style data from leaders themselves, together with actual effectiveness information, might have delivered different results.

It is recommended that future research efforts endeavour to optimise sample randomisation. Attempts to triangulate the results through qualitative approaches as well as leader sourced views and financial data to support leadership effectiveness would also be beneficial. As this study specifically concentrated on just two leadership styles, it would be valuable to include other leadership styles (such as authentic, ethical and servant) in future research. Lastly, the addition of extra predictor variables (for example, the leader's age and tenure) could allow for the predictive role of leadership style to be placed in context.

\section{Conclusion}

This study has contributed to addressing the research problem as discussed in the introduction section; the aim of the authors has thus been achieved. In particular, leader $C Q$ and its dimensions neither strengthened nor weakened the relationship between empowering leadership and leadership effectiveness. Notwithstanding statistical evidence indicating that leader CQ and its dimensions did reduce the strength of the relationship between directive leadership and leadership effectiveness, especially at lower levels of leader CQ and its dimensions, the respective impacts were too benign to suggest that such influence had any practical effect.

\section{Acknowledgements Competing interests}

The authors declare that they have no financial or personal relationships that may have inappropriately influenced them in writing this article.

\section{Authors' contributions}

A.S. performed the literature review, coordinated the statistical analysis, interpreted the data results and prepared the manuscript. R.S. provided conceptual and design input as well as commentary on the manuscript drafts.

\section{References}

Ahearne, M., Mathieu, J. \& Rapp, A., 2005, 'To empower or not to empower your sales force? An empirical examination of the influence of leadership empowerment behavior on customer satisfaction and performance', Journal of Applied behavior on customer satisfaction and performance', Journal of App A
Psychology 90(5), 945-955. https://doi.org/10.1037/0021-9010.90.5.945

Alabi, G., 2012, 'Understanding the relationship among leadership effectiveness, leader-member interactions and organizational citizenship behaviour in higher institutions of learning in Ghana', Journal of International Education Research 8(3), 263-278. https://doi.org/10.19030/jier.v8i3.7108

Alon, I., Boulanger, M., Elston, J.A., Galanaki, E., de Ibarreta, C.M., Meyers, J. et al., 2016, 'Business cultural intelligence quotient: A five-country study', Thunderbird International Business Review, viewed 12 September 2016, from http:// onlinelibrary.wiley.com/doi/10.1002/tie.21826/full

Ang, S., Van Dyne, L., Koh, C., Ng, K.Y., Templer, K.J., Tay, C. \& Chandrasekar, N.A., 2007 'Cultural intelligence: Its measurement and effects on cultural judgment and decision making, cultural adaptation and task performance', Management \& Organization Review 3(3), 335-371. https://doi.org/10.1111/j.1740-8784. 2007.00082.x

Ang, S., Van Dyne, L. \& Rockstuhl, T., 2015, 'Cultural intelligence: Origins, conceptualization, evolution, and methodological diversity', in M.J. Gelfand, C. Chiu \& Y. Hong (eds.), Handbook of advances in culture psychology, pp. 273-323, Oxford University Press, New York.

Araujo-Cabrera, Y., Suarez-Acosta, M.A. \& Aguiar-Quintana, T., 2016, 'Exploring the influence of CEO extraversion and openness to experience on firm performance: The mediating role of top management team behavioral integration', Journal of Leadership \& Organizational Studies. https://doi.org/10.1177/1548051816655991

Avery, G.C., 2004, Understanding leadership: Paradigms and cases, Sage, London.

Ayman, R. \& Korabik, K., 2010, 'Leadership: Why gender and culture matter', American Psychologist 65(3), 157-170. https://doi.org/10.1037/a0018806

Balter, R., Chow, J. \& Jin, Y., 2014, 'What diversity metrics are best used to track and improve employee diversity?', Cornell University ILR School, 1-6.

Bass, M. \& Bass, R., 2008, The Bass handbook of leadership, Free Press, New York.

Bester, J., Stander, M.W. \& Van Zyl, L.E., 2015, 'Leadership empowering behaviour, psychological empowerment, organisational citizenship behaviours and turnover
intention in a manufacturing division', SA Journal of Industrial Psychology 41(1), intention in a manufacturing division', SA Journal
1-14. https://doi.org/10.4102/sajip.v41i1.1215

Bjurstedt, A., 2007, 'Gravure vs. web-offset! The changing world of publication printing 1986-2006', PhD thesis, Royal Institute of Technology.

Bovornusvakool, W., Ardichvili, A. \& Rana, S., 2015, 'Cultural intelligence: A review of the literature', paper presented at the UFHRD Conference, University of Cork, Cork, Ireland, 3-5th June.

Butler, A.M., Kwantes, C.T. \& Boglarsky, C.A., 2014, 'The effects of self-awareness on perceptions of leadership effectiveness in the hospitality industry: A cross cultural investigation', International Journal of Intercultural Relations 40, 87-98. https:// doi.org/10.1016/j.ijintrel.2013.12.007

Caldwell, J., 2015, 'Leading globally, thinking interculturally: Developing global characteristics', Journal of Business Diversity 15(1), 55-59.

Caligiuri, P. \& Tarique, I., 2012, 'Dynamic cross-cultural competencies and global leadership effectiveness', Journal of World Business 47(4), 612-622. https://doi. org/10.1016/j.jwb.2012.01.014

Cheong, M., Spain, S.M., Yammarino, F.J. \& Yun, S., 2016, 'Two faces of empowering leadership: Enabling and burdening', The Leadership Quarterly 27(4), 602-616. https://doi.org/10.1016/j.leaqua.2016.01.006

Cicero, L., Pierro, A. \& Van Knippenberg, D., 2010, 'Leadership and uncertainty: How role ambiguity affects the relationship between leader group prototypicality and leadership effectiveness', British Journal of Management 21(2), 411-421.

Clark, K.D. \& Waldron, T., 2016, 'Predictors of leadership behavior in early career white-collar professionals: The roles of personal characteristics and career context', Journal of Leadership \& Organizational Studies 23(1), 27-38. https://doi. org/10.1177/1548051815587759

Clark, R.A., Hartline, M.D. \& Jones, K.C., 2009, 'The effects of leadership style on hotel employees' commitment to service quality', Cornell Hospitality Quarterly 50(2), 209-231. https://doi.org/10.1177/1938965508315371

Cohen, J., 1988, Statistical power analysis for behavioral sciences, Lawrence Erlbaum Associates, Mahwah, NJ.

Conway, J.M., 2000, 'Managerial performance development constructs and personality correlates', Human Performance 13(1), 23-46. https://doi.org/10.1207/ S15327043HUP1301_2

Coovert, M.D. \& McNelis, K., 1988, 'Determining the number of common factors in factor analysis: A review and program', Educational and Psychological Measurement 48(3), 687-692. https://doi.org/10.1177/0013164488483012

Costello, A.B. \& Osborne, J.W., 2005, 'Best practices in exploratory factor analysis: Four recommendations for getting the most from your analysis', Practical Assessment, Research \& Evaluation 10(7), 1-9. 
Cruz, M.G., Henningsen, D.D. \& Smith, B.A., 1999, 'The impact of directive leadership on group information sampling, decisions, and perceptions of the leader',
Communication Research 26(3), 349-369. https://doi.org/10.1177/009365099 026003004

De Cremer, D. \& Van Knippenberg, D., 2004, 'Leader self-sacrifice and leadership effectiveness: The moderating role of leader self-confidence', Organizational Behavior and Human Decision Processes 95(2), 140-155. https://doi. Behavior and Human Decision

DeCoster, J., 1998, 'Overview of factor analysis', viewed 20 July 2016, from http:// www.stat-help.com/notes.html

Deluga, R.J., 1991, 'The relationship of leader and subordinate influencing activity in naval environments', Military Psychology 3(1), 25-39. https://doi.org/10.1207/ s15327876mp0301_2

Deng, L. \& Gibson, P., 2008, 'A qualitative evaluation on the role of cultural intelligence in cross-cultural leadership effectiveness', International Journal of Leadership Studies 3(2), 181-197.

Dorfman, P., Javidan, M., Hanges, P., Dastmalchian, A. \& House, R., 2012, 'GLOBE: A twenty year journey into the intriguing world of culture and leadership', Journal of World Business 47(4), 504-518. https://doi.org/10.1016/j.jwb.2012.01.004

Du Plessis, Y., 2011, 'Cultural intelligence as managerial competence', Alternation 18(1), 28-46.

DuBrin, A.J., 2016, Leadership: Research findings, practice, and skills, 8th edn., Cengage Learning, Boston, MA.

Dziuban, C.D. \& Shirkey, E.C., 1974, 'When is a correlation matrix appropriate for factor analysis?', Psychological Bulletin 81(6), 358-361. https://doi.org/10.1037/h0036316

Earley, P.C., 2002, 'Redefining interactions across cultures and organizations: Moving forward with cultural intelligence', Research in Organizational Behavior 24, 271299. https://doi.org/10.1016/S0191-3085(02)24008-3

Earley, P.C. \& Ang, S., 2003, Cultural intelligence: Individual interactions across cultures, Stanford University Press, Redwood City, CA

Eckert, R., Ekelund, B.Z., Gentry, W.A. \& Dawson, J.F., 2010, ‘I don't see me like you see $\mathrm{me}$, but is that a problem? Cultural influences on rating discrepancy in 360 degree feedback instruments', European Journal of Work and Organizational Psychology 19(3), 259-278. https://doi.org/10.1080/13594320802678414

Egel, E. \& Fry, L.W., 2016, 'Spiritual leadership as a model for Islamic leadership', Public Integrity, viewed 10 October 2016, from http://www.tandfonline.com/doi/full/10 $.1080 / 10999922.2016 .1200411$

Ellis, S.M. \& Steyn, H.S., 2003, 'Practical significance (effect sizes) versus or in combination with statistical significance (p-values)', Management Dynamics 12(4), 51-53.

Ersoy, A., 2014, 'The role of cultural intelligence in cross-cultural leadership effectiveness: A qualitative study in the hospitality industry', Journal of Yaşa University 9(35), 6099-6108. https://doi.org/10.19168/jyu.83730

Floyd, F.J. \& Widaman, K.F., 1995, 'Factor analysis in the development and refinement of clinical assessment instruments', Psychological Assessment 7(3), 286-299. https://doi.org/10.1037/1040-3590.7.3.286

Fong, K.H. \& Snape, E., 2015, 'Empowering leadership, psychological empowerment and employee outcomes: Testing a multi-level mediating model', British Journal of Management 26(1), 126-138. https://doi.org/10.1111/1467-8551.12048

Garnett, J.L., Marlowe, J. \& Pandey, S.K., 2008, 'Penetrating the performance predicament: Communication as a mediator or moderator of organizational culture's impact on public organizational performance', Public Administration Review 68(2), 266-281. https://doi.org/10.1111/j.1540-6210.2007.00861.x

Groves, K.S. \& Feyerherm, A.E., 2011, 'Leader cultural intelligence in context: Testing the moderating effects of team cultural diversity on leader and team performance' Group \& Organization Management 36(5), 535-566. https://doi.org/10.1177/ 1059601111415664

Grubb, B.A., 2014, 'A study of authentic leadership and cultural intelligence in higher education academic leaders', PhD thesis, Indiana Wesleyan University.

Hair, J.F., Jr., Black, W.C., Babin, B.J. \& Anderson, R.E., 2010, Multivariate data analysis, 7 th edn., Prentice Hall, Upper Saddle River, NJ.

Hansbrough, T.K., Lord, R.G. \& Schyns, B., 2015, 'Reconsidering the accuracy of follower leadership ratings', The Leadership Quarterly 26(2), 220-237. https://doi. org/10.1016/j.leaqua.2014.11.006

Harris, L.S. \& Kuhnert, K.W., 2008, 'Looking through the lens of leadership: A constructive developmental approach', Leadership \& Organization Development Journal 29(1), 47-67. https://doi.org/10.1108/01437730810845298

Harrison, N., 2012, 'Investigating the impact of personality and early life experiences on intercultural interaction in internationalised universities', International Journal of Intercultural Relations 36(2), 224-237. https://doi.org/10.1016/j.ijintrel. 2011.03.007

Hassan, S., Mahsud, R., Yukl, G. \& Prussia, G.E., 2013, 'Ethical and empowering leadership and leader effectiveness', Journal of Managerial Psychology 28(2), 133-146. https://doi.org/10.1108/02683941311300252

Hendrickson, C.S., 2016, 'Interpretive leadership and cultural intelligence: A pathway toward Christian unity', in M.D. Chapman \& M. Haar (eds.), Pathways for ecclesial dialogue in the twenty-first century: Revisiting ecumenical method, pp. 101-114, Palgrave Macmillan, Hampshire.

Hinrichs, A.T., 2011, 'Motivation to lead: Examining its antecedents and consequences in a team context', PhD thesis, Texas A\&M University.

Hmieleski, K.M. \& Ensley, M.D., 2007, 'A contextual examination of new venture performance: Entrepreneur leadership behavior, top management team heterogeneity, and environmental dynamism', Journal of Organizational Behavior 28(7), 865-889. https://doi.org/10.1002/job.479
Hogan, R. \& Hogan, J., 2001, 'Assessing leadership: A view from the dark side', International Journal of Selection and Assessment 9(1/2), 40-51. https://doi. org/10.1111/1468-2389.00162

Holt, S., Bjorklund, R. \& Green, V., 2009, 'Leadership and culture: Examining the relationship between cultural background and leadership perceptions', The Journal of Global Business Issues 3(2), 149-164.

Houghton, J.D. \& Yoho, S.K., 2005, 'Toward a contingency model of leadership and psychological empowerment: When should self-leadership be encouraged" Journal of Leadership and Organizational Studies 11(4), 65-83. https://doi org/10.1177/107179190501100406

House, R., Javidan, M., Hanges, P. \& Dorfman, P., 2002, 'Understanding cultures and implicit leadership theories across the globe: An introduction to project GLOBE', Journal of World Business 37(1), 3-10. https://doi.org/10.1016/S1090 9516(01)00069-4

Hwang, S.J., Quast, L.N., Center, B.A., Chung, C.N., Hahn, H. \& Wohkittel, J., 2015, 'The impact of leadership behaviours on leaders' perceived job performance across cultures: Comparing the role of charismatic, directive, participative, and supportive leadership behaviours in the U.S and four Confucian Asian countries Human Resource Development International 18(3), 259-277. https://doi.org/10.1 080/13678868.2015.1036226

Jogulu, U.D., 2010, 'Culturally-linked leadership styles', Leadership \& Organization Development Journal 31(8), 705-719. https://doi.org/10.1108/01437731011 094766

Jonck, P. \& Swanepoel, E., 2015, 'Exploring the theoretical link between cultural and emotional intelligence: A system analysis for human resource management', South African Journal of Business Management 46(4), 77-83.

Kaiser, R.B., Hogan, R. \& Craig, S.B., 2008, 'Leadership and the fate of organizations', American Psychologist 63(2), 96-110. https://doi.org/10.1037/0003-066X.63.2.96

Kalaluhi, S., 2013, 'Leadership in context: The moderating effect of follower need for autonomy on directive leadership style, empowering leadership style, and leader effectiveness in volunteer organizations', paper presented at the Global Conference on Business and Finance Proceedings, The Institute for Business \& Finance Research, Las Vegas, 2-5th January.

Kang, S.K. \& Jin, S., 2015, 'What are the best practices to assess leadership effectiveness', Cornell University ILR School Spring, 1-6.

Kapur, N. \& Janakiram, B., 2015, 'Comparative analysis of corporate cross cultural management in IT vs non IT organizations', Cross-Cultural Management Journal 17(2), 99-114.

Kim, H. \& Yukl, G., 1995, 'Relationships of managerial effectiveness and advancement to self-reported and subordinate-reported leadership behaviors from the multilinkage model', The Leadership Quarterly 6(3), 361-377. https://doi. linkage model, The Leadership
org/10.1016/1048-9843(95)90014-4

Kim, T., Liu, Z. \& Diefendorff, J.M., 2015, 'Leader-member exchange and job performance: The effects of taking charge and organizational tenure', Journal of Organizational Behavior 36(2), 216-231. https://doi.org/10.1002/job.1971

Ko, H., 2015, 'Cross-cultural leadership effectiveness: Perspectives from non-western leaders', Management and Organizational Studies 2(4), 1-15. https://doi. org/10.5430/mos.v2n4p1

Kodwani, A.D., 2012, 'Beyond emotional intelligence (EQ): The role of cultura intelligence (CQ) on cross-border assignments', World Review of Business Research 2(4), 86-102.

Kumar, R., Anjum, B. \& Sinha, A., 2011, 'Cross-cultural interactions and leadership behaviour', Journal of Arts, Science \& Commerce 2(3), 151-160.

Kwantes, C.T. \& Boglarsky, C.A., 2007, 'Perceptions of organizational culture, leadership effectiveness and personal effectiveness across six countries', Journal of

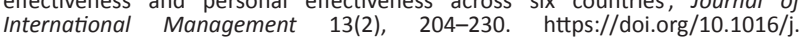
intman.2007.03.002

Lazaraton, A., 1991, 'Power, effect size, and second language research: A researcher comments', TESOL Quarterly 25(4), 759-762. https://doi.org/10.2307/3587102

Lee, S., Cheong, M., Kim, M. \& Yun, S., 2016, 'Never too much? The curvilinear relationship between empowering leadership and task performance', Group \& Organization Management, viewed 15 November 2016, from http://gom. sagepub.com/content/early/2016/04/29/1059601116646474.abstract

Levin, K.A., 2006, 'Study design III: Cross-sectional studies', Evidence-Based Dentistry 7(1), 24-25. https://doi.org/10.1038/sj.ebd.6400375

Li, M., Liu, W., Han, Y. \& Zhang, P., 2016, 'Linking empowering leadership and changeorientated organizational citizenship behavior: The role of thriving at work and orientated organizational citizenship behavior: The role of thriving at work and
autonomy orientation', Journal of Organizational Change Management, viewed 6 autonomy orientation, Journal of Organizational Change Management, viewed 6 September

Ling, Y., Wei, L., Klimoski, R.J. \& Wu, L., 2015, 'Benefiting from CEO's empowerment of TMTs: Does CEO-TMT dissimilarity matter?', The Leadership Quarterly 26(6), 1066-1079. https://doi.org/10.1016/j.leaqua.2015.07.006

Livermore, D., 2015, Leading with cultural intelligence - The real secret to success, $2 \mathrm{nd}$ edn., AMACOM, New York.

Livermore, D. \& Ang, S., 2016, 'Virtual chaos at worldwide Rx: How cultural intelligence can turn problems into solutions', in C. Barmeyer \& P. Franklin (eds.), Intercultural management - A case-based approach to achieving complementarity and synergy, pp. 167-173, Palgrave Macmillan, New York.

Lorinkova, N.M., Pearsall, M.J. \& Sims, H.P., Jr., 2013, 'Examining the differential longitudinal performance of directive versus empowering leadership in teams' Academy of Management Journal 56(2), 573-596. https://doi.org/10.5465/ amj.2011.0132

Lovvorn, A.S. \& Chen, J., 2011, 'Developing a global mindset: The relationship between an international assignment and cultural intelligence', International Journal of Business and Social Science 2(9), 275-283. 
Lowe, K.B., Kroeck, K.G. \& Sivasubramaniam, N., 1996, 'Effectiveness correlates of transformational and transactional leadership: A meta-analytic review of the MLO literature', The Leadership Quarterly 7(3), 385-425. https://doi.org/10.1016/ literature', The Leadership
S1048-9843(96)90027-2

Maggitti, P.G., Slay, H. \& Clark, K.D., 2010, 'Leadership in hypercrisis: Leading in the face of a shaken culture', Leadership Review 10, 48-67.

Mahembe, B. \& Engelbrecht, A.S., 2014, 'A preliminary study to assess the construct validity of a cultural intelligence measure on a South African sample', $S$ A Journal of Human Resource Management 12(1), 1-8. https://doi.org/10.4102/sajhrm.v12i1.558

Manamela, M.M., Cassim, N. \& Karodia, A.M., 2016, 'The impact of change management on the implementation of organisational strategy: A case study of National Home Builders Registration Council', Singaporean Journal of Business Economics and Management Studies 5(2), 1-39. https://doi. org/10.12816/0028358

Manning, T.T., 2003, 'Leadership across cultures: Attachment style influences', Journa of Leadership and Organizational Studies 9(3), 20-30. https://doi. org/10.1177/107179190300900304

Mannor, M.J., 2008, 'Top executives and global leadership: At the intersection of cultural intelligence and strategic leadership theory', in S. Ang \& L. Van Dyne (eds.), Handbook of cultural intelligence: Theory, measurement, and applications, pp. 91-106, M. E. Sharpe, New York.

Martin, S.L., Liao, H. \& Campbell, E.M., 2013, 'Directive versus empowering leadership: A field experiment comparing impacts on task proficiency and proactivity' Academy of Management Journal 56(5), 1372-1395. https://doi.org/10.5465/ amj.2011.0113

Mesterova, J., Prochazka, J., Vaculik, M. \& Smutny, P., 2015, 'Relationship between self-efficacy, transformational leadership and leader effectiveness', Journal of
Advanced 'Management Science 3(2), 109-122. https://doi.org/10.12720/ Advanced Managem

Mesu, J., Sanders, K. \& Van Riemsdijk, M., 2015, 'Transformational leadership and organisational commitment in manufacturing and service small to medium-sized enterprises - The moderating effects of directive and participative leadership', enterprises - The moderating effects of directive and participative leaders
Personnel Review 44(6), 970-990. https://doi.org/10.1108/PR-01-2014-0020

Mittal, R., 2015, Leadership: Personal effectiveness and team building, 2nd edn., Vikas Publishing House, New Delhi.

Muchiri, M.K., Cooksey, R.W., Di Milia, L.V. \& Walumbwa, F.O., 2011, 'Gender and managerial level differences in perceptions of effective leadership', Leadership \& Organization Development Journal 32(5), 462-492. https://doi.org/10.1108/ 01437731111146578

Murschetz, P., 2005, 'Interactivity and leadership effectiveness: A concept review and analysis of email as an interactive leadership tool', in L. Küng (ed.), Leadership in the media industry - Changing contexts, emerging challenges, pp. 137-153, Jönköping International Business School Ltd, Jönköping, Sweden.

Musamali, K. \& Martin, B.N., 2016, 'Comparing higher education practices and cultural competences in Kenya and the United States', Higher Education Studies 6(3), 127-137. https://doi.org/10.5539/hes.v6n3p127

Mustafa, G. \& Lines, R., 2012, 'The triple role of values in culturally adapted leadership styles', International Journal of Cross Cultural Management 13(1), 23-46. https:// doi.org/10.1177/1470595812452636

Ng, K., Van Dyne, L. \& Ang, S., 2012, 'Cultural intelligence: A review, reflections, and recommendations for future research', in A.M. Ryan, F.T.L. Leong \& F.L. Oswald (eds.), Conducting multinational research: Applying organizational psychology in (eds.), Conducting multinational research: Applying organizational psychology in
the workplace, pp. 29-58, American Psychological Association, Washington, DC.

Ng, K.Y., Van Dyne, L. \& Ang, S., 2009, 'From experience to experiential learning: Cultural intelligence as a learning capability for global leader development', Academy of Management Learning \& Education 8(4), 511-526. https://doi. Academy of Management Learning
org/10.5465/AMLE.2009.47785470

Northouse, P.G., 2013, Leadership: Theory and practice, 6th edn., Sage, Thousand Oaks, CA.

Oliverio-Olivieri, D., 2016, 'Language diversity and leadership effectiveness', International Journal of Leadership and Change 4(1), 13-22.

Osborne, J.W. \& Costello, A.B., 2009, 'Best practices in exploratory factor analysis: Four recommendations for getting the most from your analysis', Pan-Pacific Management Review 12(2), 131-146.

Oshagbemi, T., 2008, 'The impact of personal and organisational variables on the leadership styles of managers', The International Journal of Human Resource Management 19(10), 1896-1910. https://doi.org/10.1080/09585190802324130

Oyinlade, A.O., 2006, 'A method of assessing leadership effectiveness', Performance Improvement Quarterly 19(1), 25-40. https://doi.org/10.1111/j.1937-8327.2006. tb00355.x

Pallent, J., 2011, SPSS survival manual, 4th edn., Allen \& Unwin, Crows Nest.

Paulienè, R., 2012, 'Transforming leadership styles and knowledge sharing in a multicultural context', Business, Management and Education 10(1), 91-109.

Pearce, C.L. \& Sims, H.P., Jr., 2002, 'Vertical versus shared leadership as predictors of the effectiveness of change management teams: An examination of aversive, directive, transactional, transformational, and empowering leader behaviors, Group Dynamics: Theory, Research, and Practice 6(2), 172-197. https://doi org/10.1037/1089-2699.6.2.172

Pearce, C.L., Sims, H.P., Jr., Cox, J.F., Ball, G., Schnell, E., Smith, K.A. \& Trevino, L., 2003, 'Transactors, transformers and beyond - A multi-method development of a theoretical typology of leadership', Journal of Management Development 22(4), 273-307. https://doi.org/10.1108/02621710310467587

Praszkier, R., 2015, 'Empowering leadership: Embracing endogenous dynamics' Journal of Positive Management 6(2), 34-58. https://doi.org/10.12775/
JPM.2015.009
Presbitero, A., 2016, 'Culture shock and reverse culture shock: The moderating role of cultural intelligence in international students' adaptation', International Journal of Intercultural Relations 53, 28-38. https://doi.org/10.1016/j.jijintrel.2016.05.004
Int

Racicot, B.M. \& Ferry, D.L., 2016, 'The impact of motivational and metacognitive cultural intelligence on the study abroad experience', Journal of Educational Issues 2(1), 115-129. https://doi.org/10.5296/jei.v2i1.9021

Raguž, I.V., Filipović, D. \& Matijević, S., 2014, 'The significance and efficiency of multicultural teams', paper presented at the 2nd International OFEL Conference on Governance, Management and Entrepreneurship, Governance Research and Development Centre, Dubrovnik, 4-5th April.

Ramthun, A.J. \& Matkin, G.S., 2012, 'Multicultural shared leadership: A conceptual model of shared leadership in culturally diverse teams', Journal of Leadership \& Organizational Studies 19(3), 303-314. https://doi.org/10.1177/154805181 2444129

Rockstuhl, T., Seiler, S., Ang, S., Van Dyne, L. \& Annen, H., 2011, 'Beyond general intelligence (IQ) and emotional intelligence (EQ): The role of cultural intelligence (CQ) on cross-border leadership effectiveness in a globalized world', Journal of Social Issues 67(4), 825-840. https://doi.org/10.1111/j.1540-4560.2011.01730.x

Rosete, D. \& Ciarrochi, J., 2005, 'Emotional intelligence and its relationship to workplace performance outcomes of leadership effectiveness', Leadership \&

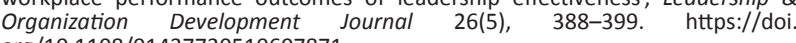
org/10.1108/01437730510607871

Sauer, S.J., 2011, 'Taking the reins: The effects of new leader status and leadership style on team performance', Journal of Applied Psychology 96(3), 574-587. https://doi.org/10.1037/a0022741

Shalhoop, J.H. \& Sanger, M.R., 2012, ‘Understanding leadership in China: Leadership profiles of state owned enterprises, multinational corporations, and major profiles of state owned enterprises, multinational corporations, and major economic trading partners', in W.H. Mobley, Y. Wang \& M. Li (eds.), Advances in
global leadership, pp. 321-348, Emerald Group Publishing Limited, Bingley, England.

Sharma, P.N. \& Kirkman, B.L., 2015, 'Leveraging leaders: A literature review and future lines of inquiry for empowering leadership research', Group \& Organization lines of inquiry for empowering leadership research', Group \& Organiza
Management 40(2), 193-237. https://doi.org/10.1177/1059601115574906

Sims, H.P., Jr., Faraj, S. \& Yun, S., 2009, 'When should a leader be directive or empowering? How to develop your own situational theory of leadership', Business Horizons 52(2), 149-158. https://doi.org/10.1016/j.bushor.2008.10.002

Statistics South Africa, 2016, Quarterly labour force survey, viewed 1 November 2016 from http://www.statssa.gov.za/publications/P0211/P02111stQuarter2016.pdf

Strydom, S.C. \& Van Eeden, R., 2013, 'Dimensions of job satisfaction identified among South African black middle-level managers: A qualitative investigation', Journal of Psychology in Africa 23(4), 579-584.

Sumner, W.G., 1906, Folkways: The sociological importance of usages, manners, customs, mores, and morals, Ginn \& Co, New York.

Sutherland, A., Edgar, D. \& Duncan, P., 2015, 'International infusion in practice - From cultural awareness to cultural intelligence', Journal of Perspectives in Applied cultural awareness to cultural intelligence', Journal of Perspectives in
Academic Practice 3(3), 32-40. https://doi.org/10.14297/jpaap.v3i3.188

Triandis, H.C., 2006, 'Cultural intelligence in organizations', Group \& Organization Management 31(1), 20-26. https://doi.org/10.1177/1059601105275253

Van Dyne, L., Ang, S. \& Koh, C., 2008a, 'Development and validation of the CQS: The cultural intelligence scale', in S. Ang \& L. Van Dyne (eds.), Handbook of cultural intelligence: Theory, measurement, and applications, pp. 16-38, M.E.Sharpe, New York.

Van Dyne, L., Ang, S. \& Livermore, D., 2010, 'Cultural intelligence: A pathway for leading in a rapidly globalizing world', in K. Hannum, B.B. McFeeters \& L. Booysen (eds.), Leading across differences, pp. 131-138, Pfeiffer, San Francisco, CA.

Van Dyne, L., Ang, S. \& Nielsen, T.M., 2008b, 'Cultural intelligence', in S.R. Clegg \& J.R. Bailey (eds.), International encyclopedia of organization studies, pp. 345-350, Sage, Thousand Oaks, CA

Weaver, C.P., Jr., 2015, 'Perceived organizational support and job overload as moderators on the relationship between leadership effectiveness and job satisfaction', Emerging Leadership Journeys 8(1), 79-100.

Widder, S., Kolthoff, D. \& Brindley, P.G., 2016, 'Leadership theories, skills, and application', in L.M. Gillman, S. Widder, M. Blaivas \& D. Karakitsos (eds.), Trauma team dynamics, pp. 15-19, Cham, Springer, Switzerland.

Wong, S.I. \& Giessner, S.R., 2016, 'The thin line between empowering and laissezfaire leadership: An expectancy-match perspective', Journal of Management viewed 2 October 2016, from http://jom.sagepub.com/content/early/2016/10/ 08/0149206315574597

Yan, J. \& Hunt, J.G., 2005, 'A cross cultural perspective on perceived leadership effectiveness', International Journal of Cross Cultural Management 5(1), 49-66. https://doi.org/10.1177/1470595805050824

Yoon, H.J., 2012, 'Predicting employee voice, behavior: An exploration of the roles of empowering leadership, power distance, organizational learning capability, and sense of empowerment in Korean organizations', PhD thesis, University of Minnesota.

Yukl, G., 1999, 'An evaluation of conceptual weaknesses in transformational and charismatic leadership theories', The Leadership Quarterly 10(2), 285-305. https://doi.org/10.1016/S1048-9843(99)00013-2

Yun, S., Cox, J. \& Sims, H.P., Jr., 2006, 'The forgotten follower: A contingency model of leadership and follower self-leadership', Journal of Managerial Psychology 21(4), 374-388. https://doi.org/10.1108/02683940610663141

Zhang, X. \& Bartol, K.M., 2010, 'Linking empowering leadership and employee creativity: The influence of psychological empowerment, intrinsic motivation, and creative process engagement', Academy of Management Journal 53(1), 107-128. https://doi.org/10.5465/AMJ.2010.48037118 